\title{
PELABELAN TOTAL SISI AJAIB SUPER PADA GRAF PRISMA BEREKOR
}

\author{
M. FAUZAN HARDI, LYRA YULIANTI, ZULAKMAL \\ Program Studi S1 Matematika, \\ Fakultas Matematika dan Ilmu Pengetahuan Alam, Universitas Andalas, \\ Kampus UNAND Limau Manis Padang, Indonesia. \\ email : mfauzanh0708@gmail.com
}

Diterima 9 Maret 2019 Direvisi 7 April 2019 Dipublikasikan 7 Mei 2019

\begin{abstract}
Abstrak. Suatu pelabelan total sisi ajaib pada graf $G$ dengan $p$ merupakan banyak titik pada graf $G$ dan $q$ merupakan banyak sisi pada graf $G$ adalah suatu fungsi bijektif $f: V(G) \cup E(G) \rightarrow\{1,2,3, \cdots, p+q\}$ sedemikian sehingga $f(u)+f(v)+f(u v)=k$, untuk setiap $u v \in E(G)$ dengan $k$ konstanta. Fungsi $f$ dikatakan sebuah pelabelan total sisi ajaib super dari graf $\mathrm{G}$ jika $f: V(G) \rightarrow\{1,2,3, \cdots, p\}$. Graf prisma berekor $\left(X_{m, n}\right)$ adalah graf yang dibentuk dari $m C_{3}$ dengan menghubungkan dua titik yang bersesuaian di $C_{3}$ dan menambahkan sebanyak $n$ buah cabang pada titik-titik di $C_{3}$ terluar. Graf Prisma Berekor $\left(X_{m, n}\right)$ memiliki pelabelan total sisi ajaib super dengan konstanta $k=9(m+n)$.

Kata Kunci: Pelabelan Total Sisi ajaib, Super, Fungsi bijektif, Graf prisma berekor, konstanta ajaib
\end{abstract}

\section{Pendahuluan}

Pelabelan merupakan suatu pemetaan satu-satu yang memetakan unsur himpunan titik dan unsur himpunan sisi ke bilangan asli yang disebut label. Pelabelan yang banyak dibahas adalah pelabelan titik (vertex labeling) yang merupakan pelabelan dengan domain himpunan titik, pelabelan sisi (edge labeling) yang merupakan pelabelan dengan domain himpunan sisi, dan pelabelan total (total labeling) yakni pelabelan dengan domain himpunan titik dan himpunan sisi. Pada pelabelan terdapat istilah bobot titik (vertex weight) yakni jumlah label titik dan label semua sisi yang terkait dengan titik tersebut. Untuk suatu sisi $u v$ yang ada di graf tersebut, jumlah label sisi dan label dua titik yang menempel pada sisi disebut bobot sisi (edge weight) yang dinotasikan dengan $w(u v)$.

Suatu pelabelan total sisi ajaib pada graf $G$ dengan $p$ merupakan banyak titik pada graf $G$ dan $q$ merupakan banyak sisi pada graf $G$ adalah suatu fungsi bijektif $f: V(G) \cup E(G) \rightarrow\{1,2,3, \cdots, p+q\}$ sedemikian sehingga $f(u)+f(v)+f(u v)=k$, untuk setiap $u v \in E(G)$ dengan $k$ konstanta. Fungsi $f$ dikatakan sebuah pelabelan total sisi ajaib super dari graf G jika $f: V(G) \rightarrow\{1,2,3, \cdots, p\}$. 


\section{Landasan Teori}

\subsection{Definisi dan Terminologi Graf}

Dalam sub bab ini akan dibahas mengenai definisi graf serta istilah dan pengertian yang terdapat di dalam graf tersebut. Graf $G=(V, E)$ terdiri dari himpunan titik vertices yang tidak kosong $V=\left\{v_{1}, v_{2}, \cdots, v_{n}\right\}$ dan himpunan $E$ yang elemenelemennya disebut sisi-sisi edges. himpunan titik dari graf $G$ dinotasikan sebagai $V(G)$ dan himpunan sisi dari graf $G$ dinotasikan dengan $E(G)$. Banyaknya titik pada graf $G$ adalah $|V(G)|$ dan banyaknya sisi pada graf $G$ adalah $|E(G)|$.

Sisi yang mempunyai titik yang sama sebagai titik ujungnya disebut loop. Sisisisi yang lebih dari satu bersesuaian dengan sebuah pasangan titik disebut sisi paralel. Graf sederhana (simple graph) adalah suatu graf yang tidak memuat loop dan tidak memuat sisi-sisi paralel. Suatu graf yang mempunyai berhingga banyaknya titik dan sisi disebut graf hingga. Graf lingkaran (circle) adalah jalan tertutup yang semua titiknya berbeda. Graf $G$ dikatakan terhubung jika untuk setiap dua titik di $G$ ada lintasan yang menghubungkan kedua titik tersebut, jika tidak demikian maka graf $G$ disebut graf tidak terhubung.

Jalan (walk) dari titik $v_{0}$ ke titik $v_{n}$ di $G$ adalah barisan hingga dari titiktitik dan sisi-sisi di $G$, ditulis $v_{0}, e_{0}, v_{1}, e_{1}, \cdots, e_{n-1}, v_{n}$ dimana $e_{i}=v_{i} v_{i+1} \in E(G)$ untuk $i=1,2, \cdots, n-1$. Jika sisi-sisi $e_{1}, e_{2}, \cdots, e_{i}$ dari suatu jalan $W$ berbeda, maka $W$ disebut suatu jejak (trail). Jika titik-titik $v_{0}, v_{1}, \cdots, v_{i}$ dari suatu jalan $W$ berbeda, maka $W$ dikatakan suatu lintasan(path). Graf lintasan adalah suatu graf dengan $n$ titik untuk $n \geq 2$, dimana terdapat tepat dua titik berderajat satu dan $n-2$ titik berderajat dua. Graf lintasan dengan $n$ titik yang dilambangkan dengan $P_{n}$, graf lintasan dengan $n$ titik memiliki $n-1$ sisi. Graf bintang adalah suatu graf yang memiliki $n$ titik berderajat 1 dan satu titik berderajat $n$.

\subsection{Graf Prisma Berekor $\left(X_{m, n}\right)$}

Graf Prisma Berekor $\left(X_{m, n}\right)$ adalah graf yang dibentuk dari sebanyak $m$ buah graf siklus $C_{3}$. Notasikan $C_{3}^{j}$ sebagai graf $C_{3}$ ke- $j$, untuk $1 \leq j \leq m$, dengan $V\left(C_{3}^{j}\right)=\left\{v 1_{j}, v 2_{j}, v 3_{j}\right\}$. Graf $X_{m, n}$ dikonstruksi dengan cara menambahkan sisi $v i_{j} v_{i_{j+1}}$ untuk $1 \leq i \leq 3$ dan $1 \leq j \leq m-1$ serta menambahkan daun sebanyak $n$ ke titik $v i_{j}$ untuk $1 \leq i \leq 3$ dan $1 \leq j \leq m$ dinotasikan titik-titik pada daun sebagai $v i_{j, k}$ untuk $1 \leq i \leq 3,1 \leq j \leq m$ dan $1 \leq k \leq n$. Dapat dilihat bahwa

$$
\begin{aligned}
V\left(X_{m, n}\right)= & \left\{v i_{j} \mid 1 \leq i \leq 3,1 \leq j \leq m\right\} \cup\left\{v i_{1, k} \mid 1 \leq i \leq 3,1 \leq k \leq n\right\}, \\
E\left(X_{m, n}\right)=\left\{v i_{1} v i_{1, k} \mid 1 \leq i \leq 3,1 \leq k \leq n\right\} \cup & \\
& \left\{v i_{j-1} v i_{j} \mid 1 \leq i \leq 3,2 \leq j \leq m\right\} \cup\left\{v 1_{j} v 2_{j} \mid 1 \leq j \leq m\right\} \cup \\
& \left\{v 1_{j} v 3_{j} \mid 1 \leq j \leq m\right\} \cup\left\{v 2_{j} v 3_{j} \mid 1 \leq j \leq m\right\}
\end{aligned}
$$

sehingga graf prisma berekor $\left(X_{m, n}\right)$ untuk $m \geq 1$ dan $n \geq 1$ memiliki $\left|V\left(X_{m, n}\right)\right|=$ $3(m+n)$ dan $\left|E\left(X_{m, n}\right)\right|=3(m+n)+3(m-1)$.

Pada paper ini akan dibahas tentang graf prisma berekor $\left(X_{m, n}\right)$ untuk $m=3$ dan $n=2$, seperti pada Gambar 1 . 


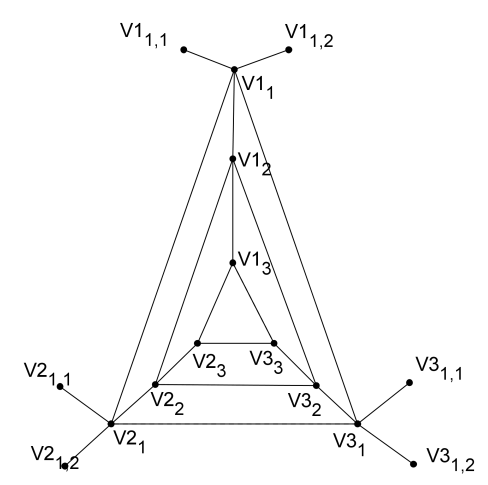

Gambar 1. Graf Prisma Berekor $X_{3,2}$.

\subsection{Pelabelan Total Sisi Ajaib Super pada Graf}

Pelabelan merupakan fungsi atau pemetaan dari unsur-unsur pada suatu graf yang berupa titik, sisi, atau titik dan sisi ke bilangan bulat positif. Pada prinsipnya, pelabelan graf merupakan pemberian nilai (label) pada titik, sisi, atau titik dan sisi. Pelabelan yang sering digunakan yaitu pelabelan titik, pelabelan sisi, dan palabelan total (titik dan sisi).

Selanjutnya, suatu pelabelan dikatakan sebagai pelabelan ajaib jika ada fungsi bijektif dari unsur-unsur pada graf yang berupa titik, sisi, atau titik dan sisi sehingga dapat menghasilkan suatu konstanta $k$ yang disebut dengan nilai ajaib (magic value). Pelabelan ajaib yang ada di antaranya pelabelan total sisi-ajaib, pelabelan total sisi-ajaib super, pelabelan total titik-ajaib, dan pelabelan total titik ajaib super [1].

Misalkan graf $G$ adalah graf dengan himpunan titik $V(G)$ dan himpunan sisi $E(G)$. Suatu pelabelan total sisi ajaib pada graf $G$ dengan $p$ titik dan $q$ sisi adalah suatu fungsi bijektif $f: V(G) \cup E(G) \rightarrow\{1,2,3, \cdots, p+q\}$ sedemikian sehingga $f(u)+f(v)+f(u v)=k$, untuk setiap $u v \in E(G)$ dengan $k$ konstanta. $f$ dikatakan sebuah pelabelan total sisi ajaib super dari graf $\mathrm{G}$ jika $f: V(G) \rightarrow\{1,2,3, \cdots, p\}$.

Teorema 2.1. [1] Graf $G$ merupakan sisi ajaib super jika dan hanya jika terdapat fungsi bijektif $f: V(G) \rightarrow\{1,2,3, \cdots, p\}$ dengan $p$ merupakan banyak titik pada graf $G$ sedemikian sehingga himpunan $S=\{f(u)+f(v) \mid u, v \in E(G)\}$ terdiri dari $q$ bilangan bulat berurutan, dimana $q$ merupakan banyak sisi pada graf $G$. Dalam hal ini $f$ dapat diperluas menjadi suatu pelabelan sisi ajaib super $G$ dengan bilangan ajaib $k=p+q+s$ dengan $s=\min (S)$ dan $S=\{k-(p+1), k-(p+2), \cdots, k-(p+$ $q)\}$ dimana $S$ merupakan hasil penjumlahan dua label titik yang berbeda dengan $s$ merupakan minimum dari $S$. 


\section{Pelabelan Total Sisi Ajaib Super pada Graf Prisma Berekor $\left(X_{3,2}\right)$}

Pada bab ini akan dibahas mengenai pelabelan total sisi ajaib super pada Graf Prisma Berekor $\left(X_{m, n}\right)$ untuk $m=3$ dan $n=2$. Pelabelan total sisi ajaib Graf Prisma Berekor $\left(X_{m, n}\right)$ memiliki konstanta ajaib yang bergantung pada cara melabelinya. Akan ditentukan pelabelan total sisi ajaib super pada Graf Prisma Berekor $\left(X_{m, n}\right)$ untuk m buah $C_{3}$ dan $n$ buah cabang.

Teorema 3.1. Terdapat pelabelan total sisi ajaib super dengan konstanta $k=45$ pada Graf Prisma Berekor $\left(X_{3,2}\right)$.

Bukti. Akan ditentukan konstanta ajaib dari pelabelan total sisi ajaib super terhadap graf prisma berekor $\left(X_{3,2}\right)$. Berdasarkan definisi graf prisma berekor, diperoleh bahwa $\left|V\left(X_{3,2}\right)\right|=3(3+2)=15$ dan $\mid E\left(X_{3,2} \mid\right)=3(3+2)+3(3-1)=21$ sesuai pada Gambar 2.

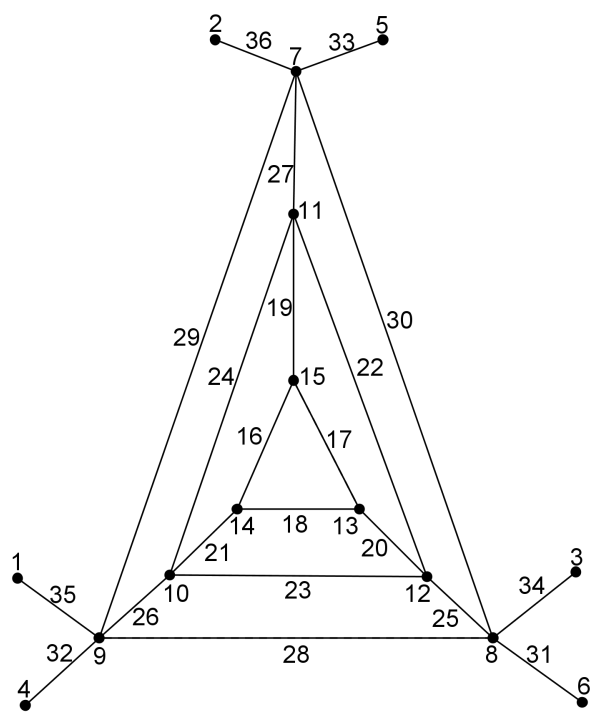

Gambar 2. Pelabelan sisi ajaib pada Graf Prisma Berekor $X_{3,2}$.

Berdasarkan pelabelan yang diperikan pada Gambar 2 diperoleh bahwa: $f\left(v 1_{1,1}\right)+f\left(v 1_{1}\right)+f\left(v 1_{1,1}\right) f\left(v 1_{1}\right)=2+7+36=45$,
$f\left(v 1_{1,2}\right)+f\left(v 1_{1}\right)+f\left(v 1_{1,2}\right) f\left(v 1_{1}\right)=5+7+33=45$,
$f\left(v 2_{1,1}\right)+f\left(v 2_{1}\right)+f\left(v 2_{1,1}\right) f\left(v 2_{1}\right)=1+9+35=45$,
$f\left(v 2_{1,2}\right)+f\left(v 2_{1}\right)+f\left(v 2_{1,2}\right) f\left(v 2_{1}\right)=4+9+32=45$,
$f\left(v 3_{1,1}\right)+f\left(v 3_{1}\right)+f\left(v 3_{1,1}\right) f\left(v 3_{1}\right)=3+8+34=45$, 


$$
\begin{aligned}
& f\left(v 3_{1,2}\right)+f\left(v 3_{1}\right)+f\left(v 3_{1,2}\right) f\left(v 3_{1}\right)=6+8+31=45, \\
& f\left(v 1_{1}\right)+f\left(v 2_{1}\right)+f\left(v 1_{1}\right) f\left(v 2_{1}\right)=7+9+29=45, \\
& f\left(v 1_{1}\right)+f\left(v 3_{1}\right)+f\left(v 1_{1}\right) f\left(v 3_{1}\right)=7+8+30=45, \\
& f\left(v 2_{1}\right)+f\left(v 3_{1}\right)+f\left(v 2_{1}\right) f\left(v 3_{1}\right)=9+8+28=45, \\
& f\left(v 1_{1}\right)+f\left(v 1_{2}\right)+f\left(v 1_{1}\right) f\left(v 1_{2}\right)=7+11+27=45, \\
& f\left(v 2_{1}\right)+f\left(v 2_{2}\right)+f\left(v 2_{1}\right) f\left(v 2_{2}\right)=9+10+26=45, \\
& f\left(v 3_{1}\right)+f\left(v 3_{2}\right)+f\left(v 3_{1}\right) f\left(v 3_{2}\right)=8+12+25=45, \\
& f\left(v 1_{2}\right)+f\left(v 2_{2}\right)+f\left(v 1_{2}\right) f\left(v 2_{2}\right)=11+10+24=45, \\
& f\left(v 1_{2}\right)+f\left(v 3_{2}\right)+f\left(v 1_{2}\right) f\left(v 3_{2}\right)=11+12+22=45, \\
& f\left(v 2_{2}\right)+f\left(v 3_{2}\right)+f\left(v 2_{2}\right) f\left(v 3_{2}\right)=10+12+23=45, \\
& f\left(v 1_{2}\right)+f\left(v 1_{3}\right)+f\left(v 1_{3}\right) f\left(v 1_{2}\right)=11+15+19=45, \\
& f\left(v 2_{2}\right)+f\left(v 2_{3}\right)+f\left(v 2_{2}\right) f\left(v 2_{3}\right)=10+14+21=45, \\
& f\left(v 3_{2}\right)+f\left(v 3_{3}\right)+f\left(v 3_{2}\right) f\left(v 3_{3}\right)=12+13+20=45, \\
& f\left(v 1_{3}\right)+f\left(v 2_{3}\right)+f\left(v 1_{3}\right) f\left(v 2_{3}\right)=15+14+16=45, \\
& f\left(v 1_{3}\right)+f\left(v 3_{3}\right)+f\left(v 1_{3}\right) f\left(v 3_{3}\right)=15+13+17=45, \\
& f\left(v 2_{3}\right)+f\left(v 3_{3}\right)+f\left(v 2_{3}\right) f\left(v 3_{3}\right)=14+13+18=45,
\end{aligned}
$$

Dapat dilihat bahwa pelabelan tersebut adalah pelabelan super. Kemudian, karena setiap sisi mempunyai bobot sisi yang sama, yatu 45, maka pelabelan pada Gambar 2 adalah pelabelan sisi ajaib super dengan konstanta ajaib $k=45$.

\section{Kesimpulan}

Suatu pelabelan total sisi ajaib pada graf $G$ dengan banyak titik $p$ dan banyak sisi $q$ adalah suatu fungsi bijektif $f: V(G) \cup E(G) \rightarrow\{1,2,3, \cdots, p+q\}$ sedemikian sehingga $f(u)+f(v)+f(u v)=k$, untuk setiap $u v \in E(G)$ dengan $k$ konstanta. Pelabelan $f$ dikatakan suatu pelabelan total sisi ajaib super dari graf G jika $f$ : $V(G) \rightarrow\{1,2,3, \cdots, p\}$.

Graf Prisma Berekor $\left(X_{3,2}\right)$ adalah graf yang dibentuk dari 3 buah graf siklus $C_{3}$ dengan menghubungkan dua titik yang bersesuaian di $C_{3}$ dan menambahkan sebanyak 2 buah cabang pada titik-titik di $C_{3}$ terluar. Diperoleh bahwa $V\left(X_{3,2}\right)=$ $\left\{v i_{j} \mid 1 \leq i \leq 3,1 \leq j \leq 3\right\} \cup\left\{v i_{1, k} \mid 1 \leq i \leq 3,1 \leq k \leq 2\right\}$ dan $E\left(X_{3,2}\right)=$ $\left\{v i_{1} v i_{1, k} \mid 1 \leq i \leq 3,1 \leq k \leq 2\right\} \cup\left\{v i_{j-1} v i_{j} \mid 1 \leq i \leq 3,2 \leq j \leq 3\right\} \cup\left\{v 1_{j} v 2_{j} \mid\right.$ $1 \leq j \leq 3\} \cup\left\{v 1_{j} v 3_{j} \mid 1 \leq j \leq 3\right\} \cup\left\{v 2_{j} v 3_{j} \mid 1 \leq j \leq 3\right\}$. Dapat dilihat bahwa $X_{3,2}$ memiliki $\left|V\left(X_{3,2}\right)\right|=15$ dan $\left|E\left(X_{3,2}\right)\right|=21$. Pada makalah ini telah diperoleh bahwa terdapat pelabelan total sisi ajaib super pada Graf Prisma Berekor $\left(X_{3,2}\right)$ dengan konstanta ajaib $k=45$.

\section{Ucapan Terima kasih}

Penulis mengucapkan terimakasih kepada Ibu Dr. Des Welyyanti, Bapak Prof. Dr. Syafrizal Sy, Bapak Dr. Dodi Devianto yang telah memberikan kritikan dan saran sehingga makalah ini dapat diselesaikan dengan baik. 
194 M. Fauzan Hardi dkk

\section{Daftar Pustaka}

[1] Baca, M dan Miller, M. 2008. Super Edge-Antimagic Graph : A wealth of Problems and Some Solutions. Brown Walker Press, USA.

[2] Bartle, R.G and Sherbert, D.R. 2000. Introduction to Real Analysis. John Wiley and Sons Inc, USA.

[3] Gallian, J.A. 2016. A Dynamic Survey of Graph Labeling. http//:www.combinatorics.org. Diakses pada 1 September 2017 Pukul 13.30.

[4] Sugeng. K.A. 2005. Magic and Antimagic Labeling of Graph. Disertasi S-3 Universitas Ballarat, Australia. 